\title{
Decision-making inflexibility in a reversal learning task is associated with severity of problem gambling symptoms but not with a diagnosis of substance use disorder
}

\author{
María F. Jara-Rizzo ${ }^{1 *} \mathbb{0}$, Juan F. Navas² ${ }^{2}$ Jose A. Rodas ${ }^{1,3}$ and José C. Perales ${ }^{4}$
}

\begin{abstract}
Background: Decisions made by individuals with disordered gambling are markedly inflexible. However, whether anomalies in learning from feedback are gambling-specific, or extend beyond gambling contexts, remains an open question. More generally, addictive disorders -including gambling disorder-have been proposed to be facilitated by individual differences in feedback-driven decision-making inflexibility, which has been studied in the lab with the Probabilistic Reversal Learning Task (PRLT). In this task, participants are first asked to learn which of two choice options is more advantageous, on the basis of trial-by-trial feedback, but, once preferences are established, reward contingencies are reversed, so that the advantageous option becomes disadvantageous and vice versa. Inflexibility is revealed by a less effective reacquisition of preferences after reversal, which can be distinguished from more generalized learning deficits.
\end{abstract}

Methods: In the present study, we compared PRLT performance across two groups of 25 treatment-seeking patients diagnosed with an addictive disorder and who reported gambling problems, and 25 matched controls [18 Males/7 Females in both groups, $\mathrm{M}_{\text {age }}\left(\mathrm{SD}_{\text {age }}\right)=25.24$ (8.42) and 24.96 (7.90), for patients and controls, respectively]. Beyond testing for differences in the shape of PRLT learning curves across groups, the specific effect of problematic gambling symptoms' severity was also assessed independently of group assignment. In order to surpass previous methodological problems, full acquisition and reacquisition curves were fitted using generalized mixed-effect models.

Results: Results showed that (1) controls did not significantly differ from patients in global PRLT performance nor showed specific signs of decision-making inflexibility; and (2) regardless of whether group affiliation was controlled for or not, gambling severity was specifically associated with more inefficient learning in phases with reversed contingencies.

Conclusion: Decision-making inflexibility, as revealed by difficulty to reacquire decisional preferences based on feedback after contingency reversals, seems to be associated with gambling problems, but not necessarily with a substance-use disorder diagnosis. This result aligns with gambling disorder models in which domain-general compulsivity is linked to vulnerability to develop gambling-specific problems with exposure to gambling opportunities.

Keywords: Addictive disorders, Gambling disorder, Gambling severity, Compulsivity, Learning inflexibility, Probabilistic reversal learning task

\footnotetext{
*Correspondence: maria.jarar@ug.edu.ec

1 Faculty of Psychology, University of Guayaquil, Guayaquil, Ecuador

Full list of author information is available at the end of the article
} original author(s) and the source, provide a link to the Creative Commons licence, and indicate if changes were made. The images or other third party material in this article are included in the article's Creative Commons licence, unless indicated otherwise in a credit line to the material. If material is not included in the article's Creative Commons licence and your intended use is not permitted by statutory regulation or exceeds the permitted use, you will need to obtain permission directly from the copyright holder. To view a copy of this licence, visit http://creativecommons.org/licenses/by/4.0/. The Creative Commons Public Domain Dedication waiver (http://creativeco mmons.org/publicdomain/zero/1.0/) applies to the data made available in this article, unless otherwise stated in a credit line to the data. 


\section{Background}

Balanced decision-making is crucial for adaptive daily functioning. Consequently, anomalies of decision-making processes are present in a range of psychopathological conditions [1-4]. In more direct relation to the aims of the present study, addiction has been described as a disorder of the ability to make good decisions, namely to make choices regarding the potentially addictive behavior (using drugs, gambling) that overcome impulses, for the sake of more beneficial long-term goals [5-7]. Individuals suffering from an addictive disorder thus persist in a harmful behavior in spite of its negative consequences (e.g. economic losses, health, family and work problems) (DSM-5 [8]). In concordance with this observation, a number of studies have tried to test the prediction that addicted patients present domain-general decisionmaking alterations that could predate the disorder onset, contribute to its chronicity or complication, or occur as a consequence of the addictive process itself [9-11].

Among the aspects of decision making that are relevant to understand addictive processes is behavioral flexibility, namely the ability to readjust preferences in response to reward contingency changes in decision-making-underambiguity tasks. Inflexibility would be manifested in a transient inability to stop choosing a given option that is no longer advantageous (perseveration), or, more generally, in a difficulty to relearn action-outcome contingencies that depart from the ones that were learnt in the initial acquisition phase.

The relevance of decision-making inflexibility for addictive behaviors stems from the fact that it is hypothesized to reflect domain-general proneness to compulsivity $[12,13]$, which, in turn, has been theorized to be a transdiagnostic vulnerability factor for addictive disorders and other psychopathologies [14, 15]. In different theories, (a) addictive behaviors transition from being goal-driven to being stimuli or context-driven (habitual/ compulsive, [16, 17]), or, alternatively, (b) addictionrelated rewards acquire a disproportionate motivational value [18]. Independently of which of these approaches is correct, it seems obvious that being unable to fine-tune the associations between decision options and outcomes, or to behave accordingly, would render the individual more vulnerable to the progression of loss of control over potentially addictive behaviors.

There are several ways to operationalize decisionmaking inflexibility in the laboratory $[19,20]$. However, none of the available protocols is sensitive only to inflexibility. Crucially, reacquisition after contingency change is inextricably linked to more general contingency learning differences, i.e. any individual differences in acquisition will contaminate gross reacquisition differences. So, detecting inflexibility previously requires experimentally dissociating acquisition learning and artifact-free (in) flexibility (for a detailed discussion on this matter and its methodological subtleties, see [21]).

This distinction is not only of methodological importance. There is some consensus that acquisition learning is computationally simpler than adjustment to unsignaled contingency changes. Extinction, for instance, is not just the vanishment of previous conditioning, but a context-dependent learning process about the omission of the reinforcer [22]. Similarly, reversal learning seems to require high-order mechanisms to restructure the set of learned associations (for an updated view, see [23]). So, once the dissociation is granted, computational modelling is required to identify the cognitive processes originating the two parts of such a dissociation [21]. Although the present study concerns only the first stage of this process, the constraints it imposes on computational modelling will be sketched in the discussion section.

\section{The probabilistic learning task and problematic gambling}

The most pervasively used task to investigate decisionmaking inflexibility in the lab is the Probabilistic Reversal Learning Task (henceforth, PRLT). In each trial of this task, two choice options are presented to the learner, one advantageous (more likely to ensue reward; e.g. virtual points or money), and the other disadvantageous (more likely to ensue some kind of punishment). Initially, the individual has no other possibility than making her decision at random, but her choices grow attuned to reward and punishment contingencies as the task progresses. However, at some point, and without prior notice, the contingencies are reversed, and the individual needs to update her preferences on the basis of the new contingencies.

As noted above, decision-making inflexibility can be used as an individual-differences measure of compulsivity [24, 25]. Unfortunately, most previous attempts to compare PRLT performance across groups of individuals with and without addictive behaviors are not free of methodological and interpretational problems. In general, there is no unanimity regarding the best way to measure inflexibility in the PRLT. In a recent metaanalysis and systematic review, van Timmeren et al. [19], found that the studies that used the PRLT do not reveal significant levels of behavioral inflexibility in individuals with gambling disorder. However, this could be due to the diversity of procedures and measures used to operationalize PRLT performance. Different studies used, for instance, the amount of money or points earned [26, 27], the number of correct choices [28-30] or the number of consecutive errors after each reversion (i.e. perseverative errors, [31, 32]). 
In the present work, we will follow Perandrés-Gómez et al's [21] approach to analyze full acquisition and reacquisition curves in a PRLT with four phases: one in which preferences are first established, and three more resulting from two contingency reversals [33]. The first aim was to determine whether group affiliation (patients with a substance use disorder with symptoms of comorbid problematic gambling vs healthy controls) has any effect on the form of learning curves in each phase, or their variation across phases. Inflexibility can be corroborated by detecting any reacquisition disadvantage in phases with reversed contingencies (2 and 4), relative the ones with contingencies in the original direction ( 1 and 3 ) that is experimentally dissociable from global differences in task performance (e.g. phase-independent learning rates or asymptotes). More importantly, we will test whether the effect of contingency reversal depends itself on group (i.e. whether patients show more signs of decision-making inflexibility than controls). Subsequently, we will specifically analyze participants' performance in relation to the severity of their problematic gambling symptoms, regardless of (or controlling for) group affiliation. By assessing the relationship between gambling severity and PRLT performance, independently of group, we intended to dissociate the effect of problematic gambling from the one of other addictive behaviors.

Decision-making inflexibility in reversed contingency phases of the PRLT has been previously reported to be associated with disordered gambling $[21,29]$. This proneness towards compulsivity would explain to some extent the easiness with which disordered gamblers adhere to an initially favorable reinforcement contingency, but are later incapable of abandoning it [34-36]. Therefore, from this perspective, PRLT inflexibility would be expected to be linked to higher severity of disordered gambling symptoms, independently of the diagnosis of other addictive disorders.

\section{Methods}

\section{Participants}

Twenty-five patients under treatment for an addictive disorder were recruited from the centers Centro de Recuperación Nueva Luz and Centro de Recuperación Integral de Alcoholismo y Drogadicción (CRIAD), from Guayaquil, Ecuador. Convenience sampling was used to recruit 25 healthy controls, as closely matched as possible with patients on relevant covariates. Some of the control participants were contacted using announcements in the School of Psychology of the University of Guayaquil, and others were recruited among acquaintances of the patients.

All patients were under treatment for at least one addictive disorder (most of them, for alcohol use
Table 1 Sociodemographic and clinical features: means, standard deviations, and Bayes factors, expressing support for the alternative hypothesis

\begin{tabular}{lllll}
\hline & Group & Mean & SD & BF $_{\mathbf{1 0}}$ \\
\hline Age & HC & 24.96 & 7.908 & 0.303 \\
\multirow{2}{*}{ Education } & Patients & 25.24 & 8.428 & \\
& HC & 14.33 & 3.131 & 4.52 \\
Income & Patients & 12.36 & 2.307 & \\
\multirow{2}{*}{ SOGS } & HC & 4.21 & 1.607 & 0.317 \\
\multirow{2}{*}{ Alcohol misuse } & Patients & 4.04 & 1.695 & \\
& HC & 0.44 & 1.08 & 106,137 \\
Drug misuse & Patients & 7.72 & 4.61 & \\
& Patients & 0.63 & 0.34 & 1274 \\
& HC & 0.02 & 0.10 & 66,121 \\
\hline
\end{tabular}

HC, healthy controls; SOGS, South Oaks Gambling Screen

disorder), and were diagnosed with the DSM-IV-TR diagnostic criteria. The inclusion criteria for both groups were: (1) being between 18 and 65 years old, and (2) no history of head trauma or neurological problems, and not to be diagnosed with any psychiatric or psychological disorder (apart from the addictive disorder in the group of patients). Patients were included in the sample and considered for further assessments and analyses only if they informed of a previous history of significant problems as a consequence of gambling. Severity of gambling symptoms was assessed with the South Oaks Gambling Screen (SOGS, Spanish version; [37]). Nineteen of the 25 patients actually scored above the SOGS threshold for gambling disorder. The 6 patients who informed to have suffered gambling problems in the past but did not meet the criteria for current gambling disorder were kept in the study sample. The sociodemographic and clinical profile of each group is reported in Table 1.

\section{Procedure}

Each participant was assessed in a single session lasting $\sim 2$ h. Patients were assessed in the rehabilitation clinics, and control participants in the premises of the School of Psychology of the University of Guayaquil. All the assessments were performed by an Ecuadorian clinical psychologist with a master's degree in neuroscience. The assessment protocol was divided into four blocks (cognitive tests, computer tasks, paper-andpencil emotion and personality tests, and a clinical interview). The order of blocks and tasks within each block were counterbalanced for all participants. The instruments used were the Wechsler Intelligence Scale for Adults-III (WAIS-III: vocabulary and matrices 
[38]), an impulsive behavior scale (UPPS-P [39]), the Sensitivity to Punishment and Sensitivity to Reward Questionnaire (SPSRQ-20 [40]), the South Oaks Gambling Screen (SOGS [38]), the MultiCAGE [41], and the Probabilistic Reversal Learning Task (PRLT [28]). Some of these were however not relevant for the purposes of this study and will not be described here (see [42]; there is an overlap of $12.6 \%$ between samples of both studies).

\section{Instruments}

The South Oaks Gambling Screen (SOGS, Spanish version; [37]) was originally based on DSM-III-R diagnostic criteria for pathological gambling, but it has been later shown to have good convergence with DSM-IVTR and DSM-5 [43]. The clinical threshold for gambling disorder has been established at mean score $\geq 5$. The Spanish version of this instrument has shown good psychometric properties (Cronbach's $\alpha=0.94$ [37]).

Alcohol and drug misuse were assessed with the eight dichotomous alcohol and drug-related items of the MultiCAGE questionnaire (Spanish version; [41]). The Spanish version of this questionnaire has shown good internal consistency as measured by Cronbach's $\alpha$ (i.e. all scales presented scores higher than 0.70 [41]). Risk of alcohol misuse was computed as the average response for the 4 alcohol-related items (0-1), and risk of drug misuse as the average for the 4 drug-related items $(0-1)$ of the scale. For the two sub-scales, the threshold for significant risk of misuse has been established at two positive responses (mean score $\geq 0.5$ ) [41].

The Probabilistic Reversal Learning Task (PRLT, [28]), is a computer-based decision-making task, in which the participants have to choose, in each trial, between two different stimuli (by mouse-clicking on one of them). The options consist of two squares of different colors, randomly shifting their positions. The task consists of four phases with 40 trials each. Within each phase, one of the options was "correct" and, when the participant chose it, a symbolic reward was given in most occasions (probabilistically). The other option was "incorrect", and the participant was notified of the error after choosing it. Participants were rewarded with virtual points, and punished by subtracting points from their account. In this way, phases 1 and 3 were phases with the original contingency sign, and 2 and 4 as phases with reversed contingencies. In phases 1 and 2, the proportion of true/false feedback was $80 / 20 \%$, whereas in Phases 3 and 4 was $70 / 30 \%$. This degradation of contingency was introduced to increase uncertainty and thus to avoid close-to-perfect performance in the late phases of the task.

\section{Statistical analyses}

The two groups (patients and controls) were first compared in relevant sociodemographics and clinical features using Bayesian Mann-Whitney tests, with default priors as implemented in open JASP software.

PRLT performance was coded trialwise. Each response in each trial was classified as correct $(R=1)$ if the colored square with the higher probability of reward (in the ongoing phase) was chosen, and incorrect $(R=0)$ if the color with the lower probability of reward was chosen.

The first PRLT analysis obeyed to a Phase $(1,2$, 3 , 4) $\times$ Trial $(1-40) \times$ Group (HC, Patients) design . Response was modeled as a binomial variable with a logit link, using Generalized Linear Mixed-effects Models (GLME), with the glmer function implemented in the lme4 $\mathrm{R}$ software package [44]. This analysis is conceptually similar to a logistic regression, but includes both random and fixed-effects factors. In the present case, Phase and Trial were used as within-participant fixed factors, and Group as a between-participant fixed factor. Participant was considered as a random-effects factor, and Trial also as a random slope at the participant level (trial|participant). Additionally, in order to reduce the number of parameters in the model, Trial was treated as a quantitative variable, and was (natural)log-transformed in order to incorporate into the models the general principle that acquisition processes are curvilinear (in relation to Trial), and can thus be modelled as approximately linear in relation to Log-trial. Log-trial was zero-centered with the standard deviation as unit (so Log-trial was expressed in a-3.16 to 1.07 scale). Standardization is just a linear transformation of the original variable, and is generally recommended for quantitative predictors in this type of models to prevent convergence problems. For presentation purposes, the scale in all figures was restituted to the 1-40 scale.

Main effects in this analysis were thus the ones of Logtrial, Phase, and Group, and the interactions among them. The effect of Phase was decomposed into three orthogonal contrasts $[\mathrm{C} 1(-1,-1,1,1), \mathrm{C} 2(1,-1$, $1,-1)$, and C3 $(-1,1,1,-1)]$. The contrast portraying evidence regarding learning inflexibility is $\mathrm{C} 2$, as it represents the differential performance in phases with reversed-sign contingencies (2nd and 4th), relative to phases with the original contingency sign (1st and 3rd). Global learning differences are however portrayed by Group and Group $\times$ Log-trial main effects.

In order to isolate the contribution of each main effect to model fitting, a saturated model was first fitted. This was contrasted against a simplified one without the Phase $\times$ Log-trial $\times$ Group interaction, using the Akaike Information Criterion (AIC) and a likelihood ratio test. If the simplified model did not lose fit, it was established 
as the reference model for further comparisons, and was further simplified by removing the two-way interactions one by one. The same procedure was repeated with marginal effects (Phase, Log-trial, and Group, with the restriction that a marginal effect cannot be removed if it is involved in any of the interactions left in the model in previous steps). Once the best-fitting model was identified, significance of each of the effects in the model was determined using the $z$ statistic, with a $p<0.05$ significance level.

A second analysis was aimed at assessing the contribution of SOGS gambling severity to PRLT (both regardless and controlling for group affiliation). A similar backwards hierarchical model fitting procedure was followed, but including SOGS Severity as an individual differences factor (instead of, or along with Group).

\section{Results}

\section{Preliminary analyses}

Each group consisted of 18 males and 7 females. Education years and Income were not available for one participant, and those two missing data points were imputed using group means. Mean and standard deviation for each group in Age, Education years, and the Monthly income scale are shown in Table 1.

Bayes factors (for the Mann-Whitney $U$ test) yielded support for the alternative hypothesis $\left(\mathrm{BF}_{10}>3\right)$ for Education years, and for the null $\left(\mathrm{BF}_{10}<1 / 3\right)$ for Age and Monthly income. In other words, the two groups were well matched in Age and Monthly income, but differed in Education years. The same analyses were performed for the SOGS, MultiCAGE drugs, and MultiCAGE alcohol. As expected, given the group sampling procedure, patients were, on average, well above the clinical threshold in the three scales, whereas controls scored clearly within the non-problematic range. Complementarily, neither Monthly income $\left(r=-0.073, \mathrm{BF}_{10}=0.201\right)$, nor Education years $\left(r=-0.194, \mathrm{BF}_{10}=0.429\right)$ substantially correlated with SOGS severity across groups.

Before proceeding to the main analyses, we also checked whether log-transforming trial number within phase served the aim of adequately capturing the hypothetical curvilinear shape of the learning function (i.e. the learning process underlying the probability of a correct choice is a linear function of Log-trial), and the shape restrictions imposed by this assumption are not as tight as to not allowing to capture variations of learning curves across levels of the other factors. With that aim in mind, three baseline models were compared (identical to the ones described in the statistical analyses section, except for the non-inclusion of Group, and how Trial was modelled). In the first one (linear), trial was not transformed; in the second one (logarithmic) trial was (natural) log-transformed before entering the model; and in the third one (polynomial) the effect of trial was decomposed into a quadratic and linear component. Both the logarithmic and the polynomial model clearly outperformed the linear one $(\mathrm{AIC}=10,509,10,492$, and 10,505, for the three models, respectively), which indicates that the learning process is better conceptualized as curvilinear function of trial. However, despite being more flexible (having less shape restrictions and thus being able to capture a broader range of curves) the polynomial model was outperformed by the logarithmic model. Or, what amounts to be the same, the increase in explained variance does not compensate the increase in complexity of the polynomial model (13 vs 9 parameters). ${ }^{1}$

\section{Between-groups differences in PRLT performance}

Table 2 shows results for the hierarchical GLME analysis. Removing the three-way interaction from the saturated model (Model 0.a vs Model 1) did not hamper model fit. Removing the Group $\times$ Phase interaction or the Group $\times$ Trail interaction did not affect model fit either (Model 2.1 and 2.3 vs Model 1). However, removing the Phase $\times$ Log-trial interaction from Model 1 (Model 2.2 vs Model 1) did hamper model fit, so that two-way interaction was retained. Further removal of Group from Model 2.4 did not hamper model fit either, so the final, bestfitting model (Model 3) did not contain any marginal or interactive effect of Group.

Table 3 presents estimates for all effects (OR, odds ratios) in models 1 and 3, along with their confidence intervals and significance levels, resulting from running the models. The directions of these effects are shown in Fig. 1. Predicted values from the saturated model show, that, as expected, the proportion of correct responses increased with Log-trial within phases; and, second, that performance in reversed phases decreased relative to acquisition-sign-contingency phases, regardless of Group. There was no significant evidence that patients made fewer correct choices in general, or in phases with reversed contingencies relative to non-reversed ones (and so the absence of Group marginal or interactive effects in the best-fitting model, and particularly of interactions involving Group $\times \mathrm{C} 2$ ).

PRLT performance as a function of SOGS gambling severity The patients group consisted of individuals receiving treatment for substance use disorders who also presented gambling problems. So, in order to test gambling

\footnotetext{
1 The capacity of the log-transformation of the Trial scale to capture the shape of learning functions is visually corroborated by the close correspondence between Figs. 1 and 2 (predicted scores from fitted models) and Additional file 1: Figures S1 and S2 (observed scores).
} 


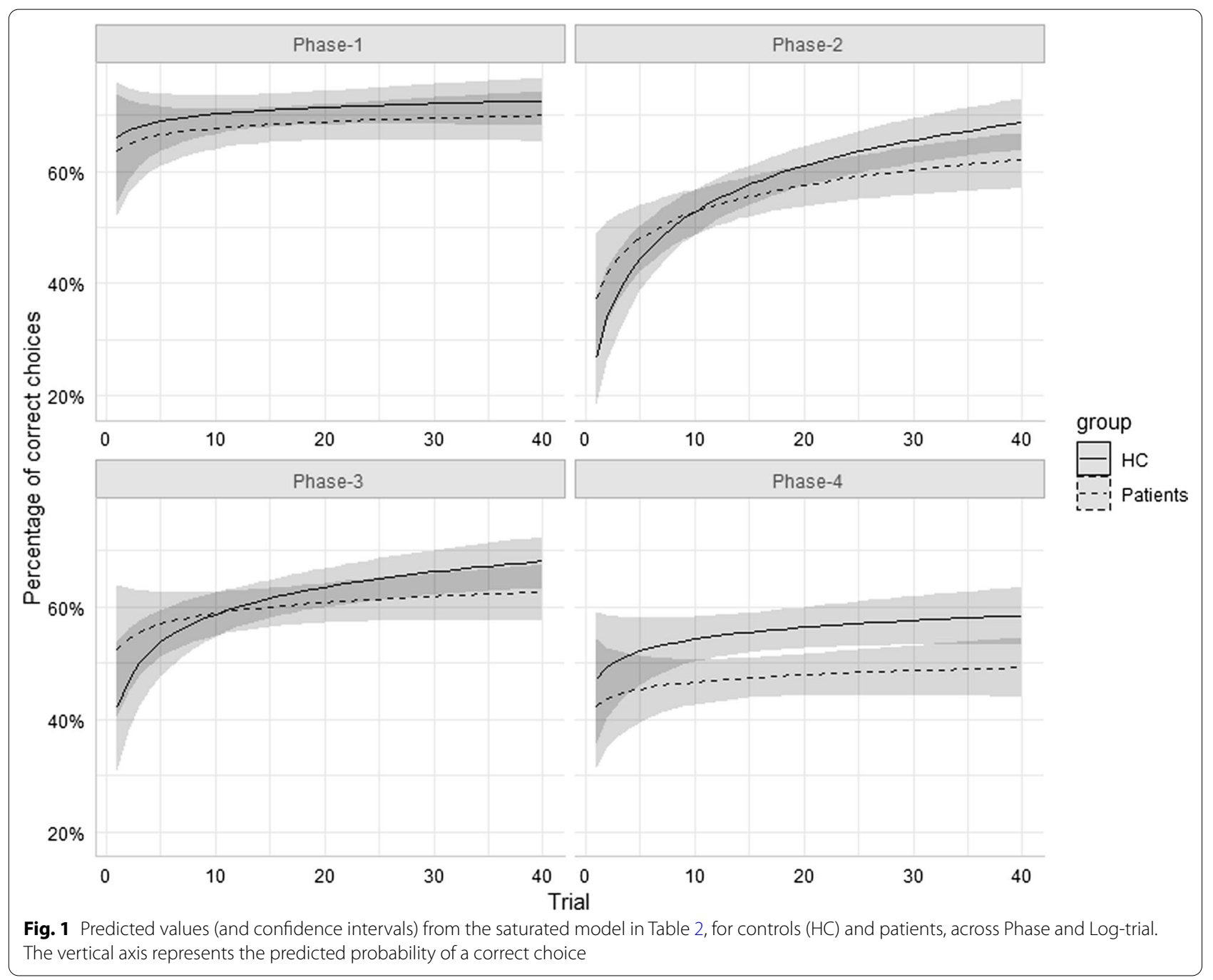

problems in a more specific way, the impact of SOGS gambling severity on PRLT was analyzed. We did so by including SOGS score as a continuous predictor, along with its interactions with Phase and Trial, in the best-fitting model from the previous analyses, and reached the best-fitting model following the hierarchical procedure described earlier (Table 4, left panel). Although Group did not have any marginal or interactive effects in previous analysis, for the sake of robustness, effects were also estimated for SOGS effects while controlling for Group and Group $\times$ Phase (i.e. Group-related effects that could explain SOGS and SOGS $\times$ Phase effects away; Table 4, right panel).

Interestingly, SOGS interaction with Phase involved only contrast C2 (see Table 5), namely the one reflecting learning inflexibility (reacquisition during phases with reversed contingencies, relative to the one in phases with the original contingency sign). The $\mathrm{C} 2$ contrast is significant in all models considered so far, i.e. learning is poorer in reversed contingency phases than in non-reversed ones. However, this pattern was more intense in high-SOGS individuals. As can be seen in Fig. 2, high-SOGS individuals showed a more intense drop in the probability of making a correct choice in Phase 2 relative to Phase 1 , and in Phase 4 relative to Phase 3, if compared with low-SOGS.

\section{Discussion}

The first aim of the present study was to test the existence of PRLT differences, and, more specifically, signs of decision-making inflexibility, in a group of patients with addictive disorders and gambling problems, 


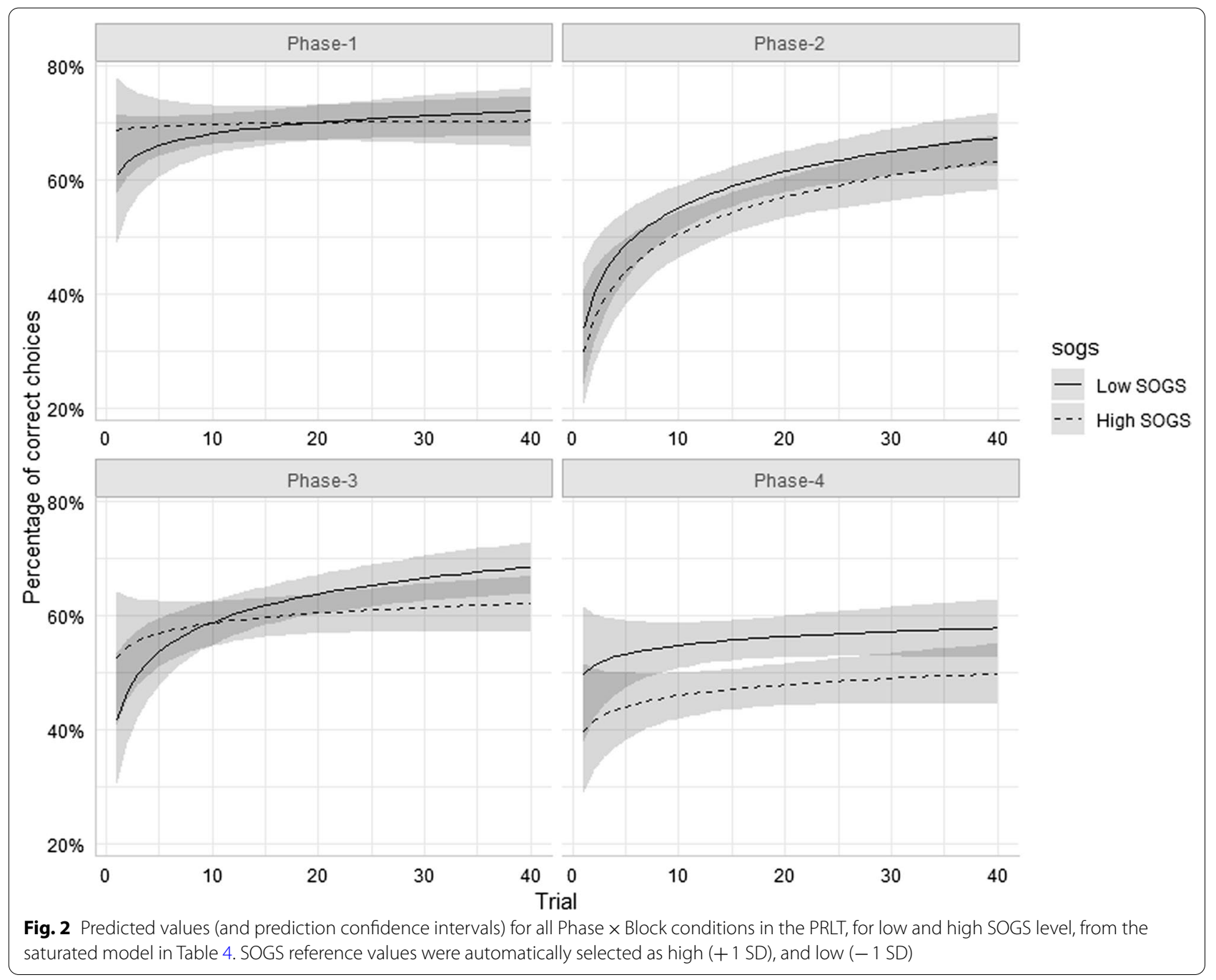

relative to matched controls. As depicted in Fig. 1 (see Additional file 1: Figure S1 for a depiction of observed, instead of predicted, responses), although patients showed less steep within-phase learning functions, between-group differences did not reach significance. ${ }^{2}$ There were no specific learning efficiency drops either in phases with reversed contingencies (phases 2 and 4), relative to non-reversed ones (phases 1 and 3). Some studies have found that addiction may have a generalized deleterious effect on feedback-based decision-making $[27,28]$, but this does not make learning necessarily more inflexible.

\footnotetext{
${ }^{2}$ This lack of significance is however likely to be due low power. Alternative analyses without the Log-trial random slope, presented in the first section of the Supplementary materials, yielded a significant Group $\times$ Log-trial effect. This effect originated in the generally slower learning functions in all Phases for the Patients group.
}

Results were contrastingly different when PRLT performance was analyzed as a function of gambling severity (measured with the SOGS questionnaire). As shown in Fig. 2 (and Additional file 1: Figure S2), participants with stronger disordered gambling symptoms made substantially fewer correct choices in phases 2 and 4, relative to phases 1 and 3, regardless of group. Or, more precisely, the more severe gambling was, the more marked this pattern grew. This result also aligns with the ones from the study by Torres et al. [29], in which gambling intensity (monthly use) was associated with increased reversal costs, restricted to reversed-contingency phases, and, especially, with Perandrés-Gómez et al.s, [21] in which patients with gambling disorder were found to behave more inflexibly in the PRLT, independently of drug use. To our knowledge, the only study in which this pattern has been reported in patients with substance use disorders is the one by Moreno-López et al. [28], where reversal learning deficits were observed to be associated with 
Table 2 Model selection for PRLT performance in the two-groups sample

\begin{tabular}{|c|c|c|c|c|c|}
\hline Model & Fixed factors & df & $A I C$ & $x^{2}$ & $p$ \\
\hline Sat. (0.a) & Group, Phase, Log-trial, 2-way interactions, 3-way interaction & 19 & 10,422 & & \\
\hline 1 & Saturated minus 3-way interaction & 16 & 10,419 & 2.418 & $\begin{array}{l}0.490 \\
(1 \geq 0 . a)\end{array}$ \\
\hline 2.1 & Model 1 minus Group × Log-trial & 15 & 10,418 & 1.418 & $\begin{array}{l}0.227 \\
(2.1 \geq 1)\end{array}$ \\
\hline $2.2^{b}$ & Model 1 minus Phase $\times$ Log-trial & 13 & 10,432 & 18.978 & $\begin{array}{l}<0.001 \\
(1>2.2)\end{array}$ \\
\hline 2.3 & Model 1 minus Phase $\times$ Group & 13 & 10,418 & 4.973 & $\begin{array}{l}0.174 \\
(2.3 \geq 1)\end{array}$ \\
\hline 2.4 & Model 1 minus Group × Log-trial and Phase $\times$ Group & 12 & 10,417 & & \\
\hline $3^{\mathrm{a}}$ & Model 2.4 minus Group & 11 & 10,416 & 0.592 & $\begin{array}{l}0.459 \\
(3 \geq 2.4)\end{array}$ \\
\hline
\end{tabular}

Significant $p$ values are in italics

a Best fitting model

b Almost singular fit (given the risk of overfitting, parameters will be estimated both for Model 1 and Model 3) (Although singular models are statistically well defined, singular fits may correspond to overfitted models with low power, and inferential procedures such as likelihood ratio tests may be inappropriate. In our case, singularity is due to the inclusion of Log-trial as a random slope in the model. Although it is theoretically sensible to assume that there are random individual differences in learning rates across participants, random slopes are not necessary to capture statistical dependency between repeated measures and thus to properly estimate within-participant effects. In view of that, and for the sake of consistency, alternative analyses without random slopes in the models are provided in the Additional file)

Sat Saturated

Table 3 Effect estimates for Model 1 and the best-fitting model (Model 3) of correct choices in the PRLT

\begin{tabular}{|c|c|c|c|c|c|c|}
\hline \multirow[t]{2}{*}{ Predictors } & \multicolumn{3}{|l|}{ Model 1} & \multicolumn{3}{|c|}{ Best-fitting model } \\
\hline & $O R$ & $\mathrm{Cl}$ & $p$ & $O R$ & $\mathrm{Cl}$ & $p$ \\
\hline Intercept & 1.62 & $1.39-1.89$ & $<0.001$ & 1.50 & $1.35-1.68$ & $<0.001$ \\
\hline Log-trial & 1.24 & $1.11-1.38$ & $<0.001$ & 1.18 & $1.09-1.28$ & $<0.001$ \\
\hline Phase C1 & 0.88 & $0.82-0.94$ & $<0.001$ & 0.86 & $0.82-0.90$ & $<0.001$ \\
\hline Phase C2 & 0.81 & $0.76-0.87$ & $<0.001$ & 0.79 & $0.76-0.83$ & $<0.001$ \\
\hline Phase C3 & 0.93 & $0.87-0.99$ & 0.021 & 0.96 & $0.92-1.01$ & 0.082 \\
\hline Group & 0.86 & $0.69-1.07$ & 0.165 & & & \\
\hline C1 $\times$ Log-trial & 0.97 & $0.92-1.01$ & 0.153 & 0.97 & $0.92-1.01$ & 0.153 \\
\hline C2 $\times$ Log-trial & 1.04 & $1.00-1.09$ & 0.077 & 1.04 & $1.00-1.09$ & 0.078 \\
\hline C3 $\times$ Log-trial & 1.09 & $1.04-1.14$ & $<0.001$ & 1.09 & $1.04-1.14$ & $<0.001$ \\
\hline Group $\times$ Log-trial & 0.91 & $0.78-1.06$ & 0.224 & & & \\
\hline $\mathrm{C} 1 \times$ Group & 0.95 & $0.87-1.05$ & 0.326 & & & \\
\hline C2 $\times$ Group & 0.95 & $0.86-1.04$ & 0.232 & & & \\
\hline C3 $\times$ Group & 1.08 & $0.98-1.18$ & 0.123 & & & \\
\hline \multicolumn{7}{|l|}{ Random effects } \\
\hline$\sigma^{2}$ & 3.29 & & & & & \\
\hline$\tau_{00}$ & $0.13_{\text {Participant }}$ & & & & & \\
\hline$\tau_{11}$ & $0.05_{\text {Log-trial||Participant }}$ & & & & & \\
\hline$\rho_{01}$ & 1.00 & & & & & \\
\hline ICC & 0.05 & & & & & \\
\hline$N$ & 50 & & & & & \\
\hline
\end{tabular}

Significant $p$ values are in italics 


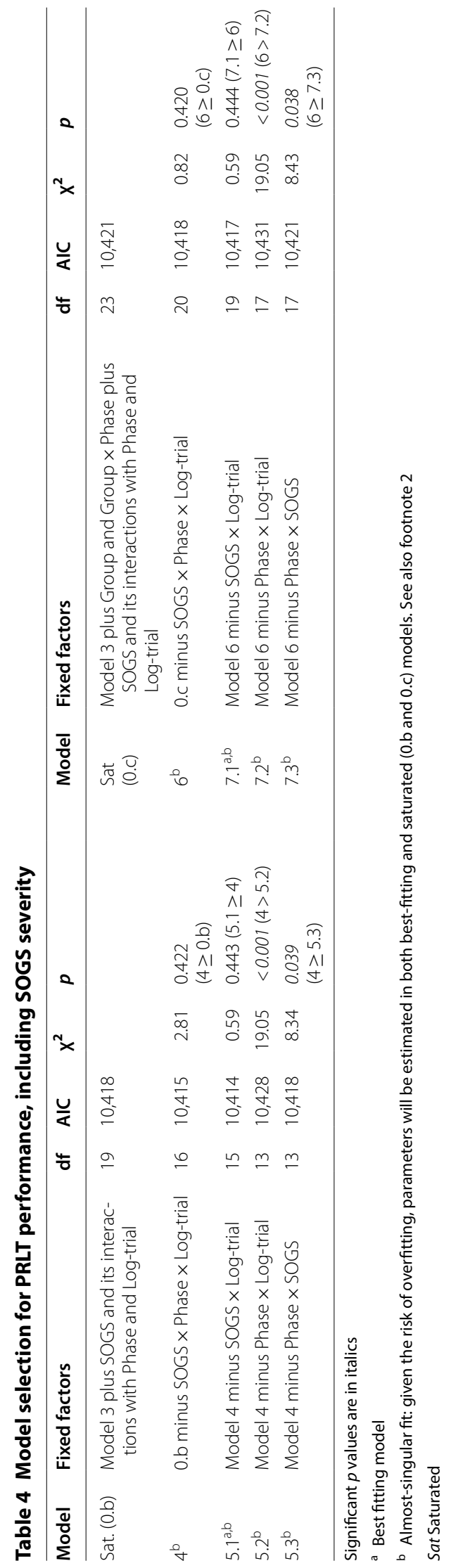


Table 5 Effect estimates for saturated (0.c) 1 and best-fitting models (7.1) of correct choices in the PRLT (controlling for Group)

\begin{tabular}{|c|c|c|c|c|c|c|}
\hline \multirow[t]{2}{*}{ Fixed effects } & \multicolumn{3}{|l|}{ Saturated model } & \multicolumn{3}{|c|}{ Best-fitting model } \\
\hline & $O R$ & $\mathrm{Cl}$ & $p$ & $O R$ & $\mathrm{Cl}$ & $p$ \\
\hline Intercept & 1.49 & $1.27-1.74$ & $<0.001$ & 1.49 & $1.27-1.74$ & $<0.001$ \\
\hline Log-trial & 1.18 & $1.09-1.28$ & $<0.001$ & 1.18 & $1.09-1.28$ & $<0.001$ \\
\hline Phase C1 & 0.85 & $0.79-0.93$ & $<0.001$ & 0.85 & $0.79-0.93$ & $<0.001$ \\
\hline Phase C2 & 0.77 & $0.70-0.83$ & $<0.001$ & 0.77 & $0.70-0.83$ & $<0.001$ \\
\hline Phase C3 & 0.89 & $0.82-0.97$ & 0.007 & 0.89 & $0.82-0.97$ & 0.007 \\
\hline Group & 1.02 & $0.82-1.27$ & 0.849 & 1.02 & $0.82-1.27$ & 0.849 \\
\hline SOGS & 0.92 & $0.80-1.05$ & 0.234 & 0.95 & $0.85-1.06$ & 0.363 \\
\hline Log-trial × C1 & 0.97 & $0.92-1.01$ & 0.158 & 0.97 & $0.92-1.01$ & 0.153 \\
\hline Log-trial × C2 & 1.04 & $1.00-1.09$ & 0.075 & 1.04 & $1.00-1.09$ & 0.075 \\
\hline Log-trial × C3 & 1.09 & $1.04-1.14$ & $<0.001$ & 1.09 & $1.04-1.14$ & $<0.001$ \\
\hline Group $\times C 1$ & 1.01 & $0.88-1.16$ & 0.870 & 1.01 & $0.88-1.16$ & 0.869 \\
\hline Group $\times C 2$ & 1.07 & $0.93-1.23$ & 0.337 & 1.07 & $0.93-1.23$ & 0.342 \\
\hline Group $\times$ C3 & 1.16 & $1.01-1.33$ & 0.039 & 1.16 & $1.01-1.33$ & 0.039 \\
\hline Log-trial × SOGS & 0.97 & $0.90-1.05$ & 0.440 & & & \\
\hline $\mathrm{SOGS} \times \mathrm{C} 1$ & 0.96 & $0.90-1.03$ & 0.258 & 0.96 & $0.90-1.03$ & 0.261 \\
\hline $\mathrm{SOGS} \times \mathrm{C2}$ & 0.92 & $0.86-0.99$ & 0.019 & 0.92 & $0.86-0.99$ & 0.018 \\
\hline $\mathrm{SOGS} \times \mathrm{C} 3$ & 0.95 & $0.89-1.02$ & 0.160 & 0.95 & $0.89-1.02$ & 0.163 \\
\hline Log-trial × SOGS × C1 & 0.99 & $0.95-1.04$ & 0.776 & & & \\
\hline Log-trial × SOGS × C2 & 1.04 & $0.99-1.09$ & 0.119 & & & \\
\hline Log-trial × SOGS × C3 & 0.99 & $0.94-1.04$ & 0.651 & & & \\
\hline \multicolumn{7}{|l|}{ Random effects } \\
\hline$\sigma^{2}$ & 3.29 & & & & & \\
\hline$\tau_{00}$ & $0.13_{\text {Participant }}$ & & & & & \\
\hline$\tau_{11}$ & $0.05_{\text {Log-trial|Participant }}$ & & & & & \\
\hline$\rho_{01}$ & 1.00 & & & & & \\
\hline ICC & 0.05 & & & & & \\
\hline $\mathrm{N}$ & 50 & & & & & \\
\hline
\end{tabular}

Significant $p$ values are in italics

cocaine use severity and diminished cerebellar gray matter volume.

In summary, according to our results, restricted effects on reversal deficits (namely, specific difficulties in learning reversed contingencies), can arise independently of differences in general learning deficiencies in the PRLT. As shown here, only the former seem to be associated with degrees of gambling severity; value updating of choice options seems to be more hindered in more severe gamblers.

Beyond this effect, this work also presents some methodological advances. So far, PRLT performance had been assessed either by extracting summary performance indices (e.g. number of perseverative errors; [30,31]) or analyzing learning curves in a blockwise fashion (number of correct responses per 5-trial or 10-trial block: [28, 29]). These summary parameters, however, present interpretation problems. For instance, individuals reaching higher learning asymptotes in the preceding phase tend to perform transitorily worse in the first trials of the ongoing phase. This means that assessing decision-making inflexibility by means of perseverative errors is likely to confound 'true' and 'apparent' perseverative errors, with the latter being attributable to pre-reversal differences. Blockwise analyses, in turn, are likely to be insensitive to effects that occur in the trial-by-trial scale. Moreover, our trialwise analyses of responses allows to model them as they really are, dichotomous (0/1) responses, instead of response counts (number of perseverative errors, number of correct choices per block) with distributional features that are seldomly taken into account in standard, general linear model-based analyses.

Taken together, results fit well in the Gambling Space Model formulated by Navas et al. [45] (see also [42, 46]). In this model, articulated as a development of the seminal Pathways Model [47], transition from recreational to 
disordered gambling is driven by the kind of reinforcement schedules that have been experimentally shown to also facilitate transition from goal-driven to compulsive behaviors. This transition towards 'gambling-specific' compulsivity can be speeded or made more likely in vulnerable individuals showing trait-like signs of compulsivity (as also shown by animal translational research; [48]). In view that in gambling disorder there is no chemical agent to hijack reinforcement circuits, individual differences in compulsivity proneness could play a larger role than in substance use disorders. Tentatively, this could explain why signs of compulsivity are easier to detect in patients with gambling disorder than in other populations of addicted individuals, and also why, in the present study, decision-making inflexibility did not emerge in the between-group comparison, but did when gambling severity was specifically taken into consideration.

As noted in the introduction, modelling inflexibility in computational terms is beyond our current aims. However, inflexibility, as operationalized here, arises as a behavioral pattern these models must be able to accommodate. For instance, the experience-weighted attraction model [EWA; 49, 50], includes an experience weight parameter $(\rho)$ to capture the well-known fact that updating becomes slower as experience accumulates. Our finding that high-SOGS individuals are more prone to persevere in the phase of negative feedback (during reversed phases) is likely to be accounted for by an increased experience decay factor, as opposed to more aspects of reward learning (i.e. learning rate, $\alpha)$. Alternatively, our and Perandrés-Gómez et al.s [21] results may be explained by differences in more complex (sequential) exploratory behavior as captured by another recent model [VSE; 51]. An example of how parameters included in computational models, estimated from behavior in decision-making-under-ambiguity tasks (i.e. the Iowa Gambling Task), can be used as individual differences variables to predict clinically-relevant gambling behavior can be found in a recent work by Kildahl et al. [52].

\section{Limitations and final remarks}

The present work is not free of limitations. First, convenience sampling did not allow carrying out an a priori power analysis. Although taking all observations into account increases power (relative to, for example, blockwise analyses), 25 participants per group are probably still insufficient to reach adequate power for all relevant effects.

Second, the cross-sectional nature of the study does not allow either to make strong claims about causal directionality. More specifically, the fact that inflexibility is associated with gambling severity is no direct proof that gambling severity and inflexibility are causally related in one way or the other.

And third, and relatedly, controlling for group (that is, for the diagnosis of a substance use disorder) when testing SOGS-inflexibility association does not stand as a strong control of other potentially relevant variables as, for example, cognitive deterioration or drug use beyond the established diagnosis. Although MultiCAGE measures are available for all participants, this questionnaire is a screening test, and thus not adequate as a continuous measure of addiction severity.

In summary, the evidential value of the present findings must be assessed in combination with previously reported signs of proneness to learning inflexibility (i.e. domain-general compulsivity) in patients with disordered gambling. Seemingly, inconsistency in previous research can be attributed to differences in the way in which learning inflexibility in the Probabilistic Reversal Learning Task (PRLT) is operationalized. In the present study, we adopted a mostly-data driven approach to identify specific signs of learning inflexibility (anomalies restricted to reacquisition in phases with a reversed contingency sign). Only patients with more severe symptoms of problematic gambling showed specific signs of learning inflexibility. These results align with gambling disorder models in which domain-general compulsivity is linked to vulnerability to develop gambling-specific problems with exposure to gambling opportunities.

\section{Supplementary information}

Supplementary information accompanies this paper at https://doi. org/10.1186/s40359-020-00482-6.

Additional file 1. Supplementary analyses.

\section{Abbreviations}

AIC: Akaike Information Criterion; CRIAD: Centro de Recuperación Nueva Luz and Centro de Recuperación Integral de Alcoholismo y Drogadicción; DSM-V: Diagnostic and Statistical Manual of Mental Disorders, Fifth Edition; DSM-IV: Diagnostic and Statistical Manual of Mental Disorders, Fourth Edition; EWA: Experience-weighted attraction model; GLME: Generalized Linear Mixedeffects Models; HC: Healthy controls; PRLT: Probabilistic Reversal Learning Task; Sat: Saturated; SOGS: South Oaks Gambling Screen; SPSRQ-20: Sensitivity to Punishment and Sensitivity to Reward Questionnaire-20 items; UPPSP: Urgency, Premeditation, Perseverance, Sensation seeking, and Positive urgency Impulsive Behavior Scale; VSE: Value plus Sequential Exploration model; WAIS-III: Wechsler Adult Intelligence Scale, Third Edition.

\section{Acknowledgements}

We gratefully thank Pedro Vargas, MSc., from University of Guayaquil, for sponsoring us to contact the rehabilitation clinics, and the staff of the rehabilitation clinics themselves, Nueva Luz and Centro de Rehabilitación Integral de Alcoholismo y Drogadicción, Guayaquil, Ecuador, for their collaboration.

Authors' contributions

MFJ-R, JFN and JCP conceived the study. MJF-R recruited the sample and performed the study. JCP performed the statistical analyses. MFJ-R drafted the 
first version of the paper. JAR collaborated in writing the first version of the paper. All authors participated in rewriting and revising the manuscript, and approved the final version. All authors read and approved the final manuscript.

\section{Funding}

MFJ-R was funded by the scholarship program offered by the University of Guayaquil-Ecuador (Programa de Becas para Profesores de la UG; Convocatoria 2015). JCP and JFN's contributions are supported by a grant from the Spanish Government (Ministerio de Economía y Competitividad, Secretaría de Estado de Investigación, Desarrollo e Innovación; Convocatoria 2017 de Proyectos I+D de Excelencia, Spain; co-funded by the Fondo Europeo de Desarrollo Regional, FEDER, European Comission), with reference number PSI2017-85488-P. The funding bodies had no role in the design, collection, analysis, and interpretation of data.

\section{Availability of data and materials}

The open database and code files for these analyses are available without restriction at the Open Science Framework website (https://osf.io/qbejc/).

\section{Ethics approval and consent to participate}

All participants were informed about the aims and characteristics of the study and signed a written consent form. The procedure was performed in accordance with the seventh revision of the Declaration of Helsinki (2013) and was approved by the Ethics Committee of the Faculty of Psychology, University of Guayaquil.

\section{Consent for publication}

Participants were informed about the evaluation process and how their data would be handled. All participants authorized their data to be used for scientific publications. All authors also approved the publication of its article in its present form.

\section{Competing interests}

The authors have no conflicts of interest to declare.

\section{Author details \\ ${ }^{1}$ Faculty of Psychology, University of Guayaquil, Guayaquil, Ecuador. ${ }^{2}$ Depart- ment of Clinical Psychology, Complutense University of Madrid, Madrid, Spain. ${ }^{3}$ School of Psychology, University College Dublin, Dublin, Ireland. ${ }^{4}$ Depart- ment of Experimental Psychology; Mind, Brain and Behavior Research Centre (CIMCYC), University of Granada, Granada, Spain.}

Received: 18 September 2019 Accepted: 28 October 2020 Published online: 10 November 2020

\section{References}

1. Blair RJR. The neurobiology of psychopathic traits in youths. Nat Rev Neurosci. 2013. https://doi.org/10.1038/nrn3577.

2. Dekkers TJ, Popma A, van Rentergem JAA, Bexkens A, Huizenga HM. Risky decision-making in attention-deficit/hyperactivity disorder: a metaregression analysis. Clin Psychol Rev. 2016. https://doi.org/10.1016/j. cpr.2016.03.001.

3. Rotge JY, Poitou C, Fossati P, Aron-Wisnewsky J, Oppert JM. Decisionmaking in obesity without eating disorders: a systematic review and meta-analysis of lowa gambling task performances. Obes Rev. 2017. https ://doi.org/10.1111/obr.12549.

4. Tchanturia K, Liao PC, Uher R, Lawrence N, Treasure J, Campbell IC. An investigation of decision-making in anorexia nervosa using the lowa Gambling Task and skin conductance measurements. J Int Neuropsychol Soc. 2007. https://doi.org/10.1017/S1355617707070798.

5. Bechara A, Damasio H. Decision-making and addiction (part I): impaired activation of somatic states in substance dependent individuals when pondering decisions with negative future consequences. Neuropsychologia. 2002. https://doi.org/10.1016/S0028-3932(02)00015-5.

6. Rachlin $\mathrm{H}$. The science of self-control. Cambridge: Harvard University Press; 2000 .
7. Verdejo-Garcia A. Neuroclinical assessment of addiction needs to incorporate decision-making measures and ecological validity. Biol Psychiatr. 2017. https://doi.org/10.1016/j.biopsych.2016.07.015.

8. American Psychiatric Association. Diagnostic and statistical manual of mental disorders. 5th ed. Washington, DC: American Psychiatric Association; 2013.

9. Clark L, Robbins TW. Decision-making deficits in drug addiction. Trends Cognit Sci. 2002. https://doi.org/10.1016/S1364-6613(02)01960-5.

10. Noël X, Brevers D, Bechara A. A neurocognitive approach to understanding the neurobiology of addiction. Curr Opin Neurobiol. 2013. https://doi. org/10.1016/j.conb.2013.01.018.

11. Verdejo-Garcia A, Lawrence AJ, Clark L. Impulsivity as a vulnerability marker for substance-use disorders: review of findings from high-risk research, problem gamblers and genetic association studies. Neurosci Biobehav. 2008. https://doi.org/10.1016/j.neubiorev.2007.11.003.

12. Berridge $\mathrm{KC}$, Robinson TE. Liking, wanting, and the incentive-sensitization theory of addiction. Am Psychol. 2016. https://doi.org/10.1037/amp00 00059.

13. Lüscher C, Robbins TW, Everitt BJ. The transition to compulsion in addiction. Nat Rev Neurosci. 2020. https://doi.org/10.1038/s41583-020-0289-z.

14. Murphy FC, Michael A, Robbins TW, Sahakian BJ. Neuropsychological impairment in patients with major depressive disorder: the effects of feedback on task performance. Psychol Med. 2003. https://doi. org/10.1017/S0033291702007018.

15. Yücel M, Oldenhof E, Ahmed SH, Belin D, Billieux J, Bowden-Jones H, et al. A transdiagnostic dimensional approach towards a neuropsychological assessment for addiction: an international Delphi consensus study. Addiction. 2019. https://doi.org/10.1111/add.14424.

16. Everitt BJ, Robbins TW. Drug addiction: updating actions to habits to compulsions ten years on. Ann Rev Psychol. 2016. https://doi. org/10.1146/annurev-psych-122414-033457.

17. O'Doherty JP, Cockburn J, Pauli WM. Learning, reward, and decision making. Ann Rev Psychol. 2017. https://doi.org/10.1146/annurev-psych-01041 6-044216.

18. Lamb RJ, Ginsburg BC. Addiction as a BAD, a behavioral allocation disorder. Pharmacol Biochem Behav. 2018. https://doi.org/10.1016/j. pbb.2017.05.002.

19. Van Timmeren T, Daams JG, Van Holst RJ, Goudriaan AE. Compulsivityrelated neurocognitive performance deficits in gambling disorder: a systematic review and meta-analysis. Neurosci Biobehav Rev. 2018. https ://doi.org/10.1016/j.neubiorev.2017.11.022.

20. D'Cruz AM, Ragozzino ME, Mosconi MW, Shrestha S, Cook EH, Sweeney JA. Reduced behavioral flexibility in autism spectrum disorders. Neuropsychology. 2013. https://doi.org/10.1037/a0031721.

21. Perandrés-Gómez A, Navas JF, van Timmeren T, Perales JC. Decisionmaking (in) flexibility in gambling disorder. Addict Behav. 2020. https:// doi.org/10.1016/j.addbeh.2020.106534.

22. Bouton ME. Extinction of instrumental (operant) learning: interference, varieties of context, and mechanisms of contextual control. Psychopharmacology. 2019. https://doi.org/10.1007/s00213-018-5076-4.

23. Izquierdo A, Brigman JL, Radke AK, Rudebeck PH, Holmes A. The neural basis of reversal learning: an updated perspective. Neuroscience. 2017. https://doi.org/10.1016/j.neuroscience.2016.03.021.

24. Fernández-Serrano MJ, Perales JC, Moreno-López L, Pérez-García M, Verdejo-Garcia A. Neuropsychological profiling of impulsivity and compulsivity in cocaine dependent individuals. Psychopharmacology. 2012. https://doi.org/10.1007/s00213-011-2485-z.

25. Fernández-Serrano MJ, Perales JC, Moreno- López L, Santos-Ruiz A, PérezGarcía M, Verdejo-Garcia A. Impulsividad y compulsividad en individuos dependientes de cocaína. Adicciones. 2012. https://doi.org/10.20882/ adicciones.102.

26. de Ruiter MB, Veltman DJ, Goudriaan AE, Oosterlaan J, Sjoerds Z, van den BrinkW. Response perseveration and ventral prefrontal sensitivity to reward and punishment in male problem gamblers and smokers. Neuropsychopharmacology. 2009. https://doi.org/10.1038/npp.2008.175.

27. Thompson SJ, Corr PJ. A feedback-response pause normalises response perseveration deficits in pathological gamblers. Int J Mental Health Addict. 2013. https://doi.org/10.1007/s11469-013-9440-7.

28. Moreno-López L, Perales JC, van Son D, Albein-Urios N, SorianoMas C, Martinez-Gonzalez JM, et al. Cocaine use severity and cerebellar gray matter are associated with reversal learning deficits 
in cocaine-dependent individuals. Addict Biol. 2015. https://doi. org/10.1111/adb.12143.

29. Torres A, Catena A, Cándido A, Maldonado A, Megías A, Perales JC. Cocaine dependent individuals and gamblers present different associative learning anomalies in feedback-driven decision-making: a behavioral and ERP study. Front Psychol. 2013. https://doi.org/10.3389/fpsyg 2013.00122.

30. Verdejo-Garcia A, Clark L, Verdejo-Roman J, Albein-Urios N, MartinezGonzalez JM, Gutierrez B, Soriano-Mas C. Neural substrates of cognitive flexibility in cocaine and gambling addictions. Br J Psychiatr. 2015. https ://doi.org/10.1192/bjp.bp.114.152223.

31. Ersche KD, Roiser JP, Robbins TW, Sahakian BJ. Chronic cocaine but not chronic amphetamine use is associated with perseverative responding in humans. Psychopharmacology. 2008. https://doi.org/10.1007/s0021 3-007-1051-1.

32. Janssen LK, Sescousse G, Hashemi MM, Timmer MHM, ter Huurne NP, Geurts DEM, Cools R. Abnormal modulation of reward versus punishment learning by a dopamine D2-receptor antagonist in pathological gamblers. Psychopharmacology. 2015. https://doi.org/10.1007/s0021 3-015-3986-y.

33. Navas JF, Torres A, Vilar R, Verdejo-Garcia A, Catena A, Perales JC. Nonmonetary decision-making indices discriminate between different behavioral components of gambling. J Gambl Stud. 2015. https://doi.org/10.1007/ s10899-014-9482-1.

34. Billieux J, Van der Linden M, Khazaal Y, Zullino D, Clark L. Trait gambling cognitions predict near-miss experiences and persistence in laboratory slot machine gambling. Br J Psychol. 2012. https://doi.org/10.1111/ bjop.2012.103.issue-3.

35. Michalczuk R, Bowden-Jones H, Verdejo-Garcia A, Clark L. Impulsivity and cognitive distortions in pathological gamblers attending the UK National Problem Gambling Clinic: a preliminary report. Psychol Med. 2011. https ://doi.org/10.1017/S003329171100095X.

36. Worhunsky PD, Malison RT, Rogers RD, Potenza MN. Altered neural correlates of reward and loss processing during simulated slot-machine fMRI in pathological gambling and cocaine dependence. Drug Alcohol Dep. 2014. https://doi.org/10.1016/j.drugalcdep.2014.09.013.

37. Echeburúa E, Báez C, Fernández-Montalvo J, Páez D. Cuestionario de juego patológico de South Oaks (SOGS): Validación española [The South Oaks Gambling Screen (SOGS); Spanish validation]. Anál Modif Conducta. 1994;20:769-91.

38. Wechsler D. Wechsler Intelligence Scale for Adults-III (WAIS-III). Madrid: TEA Ediciones; 2001

39. Cándido A, Orduña E, Perales JC, Verdejo-Garcia A, Billieux J. Validation of a short Spanish version of the UPPS-P impulsive behaviour scale. Trastor Adict. 2012. https://doi.org/10.1016/S1575-0973(12)70048-X.

40. Aluja A, Blanch A. Neuropsychological behavioral inhibition system (BIS) and behavioral approach system (BAS) assessment: a shortened sensitivity to punishment and sensitivity to reward questionnaire version (SPSRQ-20). J Personal Assessm. 2011. https://doi.org/10.1080/00223 891.2011 .608760$.
41. Pedrero-Pérez E, Rodríguez-Monje MT, Gallardo-Alonso F, FernándezGirón M, Pérez-López M, Chicharro-Romero J. Validación de un instrumento para la detección de trastornos de control de impulsos y adicciones: el MULTICAGE CAD-4. Trastor Adict. 2007. https://doi.org/10.1016/ S1575-0973(07)75656-8.

42. Jara-Rizzo MF, Navas JF, Catena A, Perales JC. Types of emotion regulation and their associations with gambling: a cross-sectional study with disordered and non-problem ecuadorian gamblers. J Gambl Stud. 2019. https ://doi.org/10.1007/s10899-019-09868-7.

43. Stinchfield R, McCready J, Turner NE, Jimenez-Murcia S, Petry NM, Grant J, et al. Reliability, validity, and classification accuracy of the DSM-5 diagnostic criteria for gambling disorder and comparison to DSM-IV. J Gambl Stud. 2016. https://doi.org/10.1007/s10899-015-9573-7.

44. Bates D, Maechler M, Bolker B, Walker S. Fitting linear mixed-effects models using Ime4. J Stat Softw. 2014. https://arxiv.org/abs/1406.5823. Accessed 20 Sept 2018

45. Navas JF, Billieux J, Verdejo-Garcia A, Perales JC. Neurocognitive components of gambling disorder: implications for policy, prevention, and treatment. In: Bowden-Jones H, Dickson C, Dunand C, Simon O, editors. Harm reduction for problem gambling: a public health approach. London: Routledge; 2019.

46. Ruiz de Lara CM, Navas JF, Perales JC. The paradoxical relationship between emotion regulation and gambling-related cognitive biases. PLoS ONE. 2019. https://doi.org/10.1371/journal.pone.0220668.

47. Blaszczynski A, Nower L. A pathways model of problem and pathological gambling. Addiction. 2002. https://doi.org/10.104 6/j.1360-0443.2002.00015.x.

48. Fineberg NA, Potenza MN, Chamberlain SR, Berlin HA, Menzies L, Bechara A, et al. Probing compulsive and impulsive behaviors, from animal models to endophenotypes: a narrative review. Neuropsychopharmacology. 2010. https://doi.org/10.1038/npp.2009.185.

49. Camerer $\mathrm{C}$, Hua HT. Experience-weighted attraction learning in normal form games. Econometrica. 1999. https://doi.org/10.1111/14680262.00054 .

50. den Ouden HE, Daw ND, Fernandez G, Elshout JA, Rijpkema M, Hoogman $\mathrm{M}$, et al. Dissociable effects of dopamine and serotonin on reversal learning. Neuron. 2013. https://doi.org/10.1016/j.neuron.2013.08.030.

51. Ligneul R. Sequential exploration in the lowa gambling task: validation of a new computational model in a large dataset of young and old healthy participants. PLoS Comput Biol. 2019. https://doi.org/10.1371/journ al.pcbi. 1006989.

52. Kildahl N, Hansen S, Brevers D, Skewes J. Individual differences in learning during decision-making may predict specific harms associated with gambling. Addict Behav. 2020. https://doi.org/10.1016/j.addbeh.2020.106496.

\section{Publisher's Note}

Springer Nature remains neutral with regard to jurisdictional claims in published maps and institutional affiliations.
Ready to submit your research? Choose BMC and benefit from:

- fast, convenient online submission

- thorough peer review by experienced researchers in your field

- rapid publication on acceptance

- support for research data, including large and complex data types

- gold Open Access which fosters wider collaboration and increased citations

- maximum visibility for your research: over $100 \mathrm{M}$ website views per year

At BMC, research is always in progress.

Learn more biomedcentral.com/submissions 